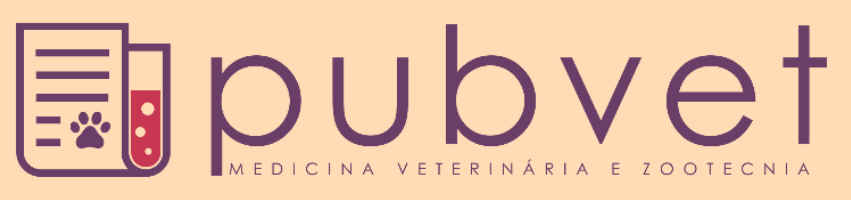

https://doi.org/10.31533/pubvet.v14n1a496.1-7

\title{
Avaliação de diferentes alturas de corte na ensilagem de milho ${ }^{1}$
}

\author{
Luiz Anselmo Souza ${ }^{2}$, Wellyngton Tadeu Vilela Carvalho ${ }^{3 *}$, Renata Vitarele Gimenes Pereira ${ }^{30}$, \\ Hemerson Alves de Faria ${ }^{30}$, Duarte Carvalho Minighin ${ }^{3}{ }^{\circ}$, Queila Gouveia Tavares ${ }^{2}{ }^{\circ}$, Carlos Henrique \\ Milagres Ribeiro $^{4}{ }^{\circ}$, Lucas Vieira Silva ${ }^{2} \theta$, Luiz Edvaldo Teixeira ${ }^{\circ}{ }^{\circ}$, Guilherme Almeida Martins ${ }^{2}$ \\ ${ }^{I}$ Trabalho de Conclusão de Curso do primeiro autor \\ ${ }^{2}$ Engenheiro Agrônomo pelo Instituto Federal de Educação, Ciência e Tecnologia do Sudeste MG - Campus Barbacena \\ ${ }^{3}$ Professor do Instituto Federal do Sudeste de Minas Gerais - Campus Barbacena, Departamento de Zootecnia, Barbacena - MG, Brasil. \\ ${ }^{4}$ Graduando em Engenharia Agronômica pelo Instituto Federal de Educação, Ciência e Tecnologia do Sudeste MG - Campus Barbacena. \\ ${ }^{5}$ Funcionário do Instituto Federal de Educação, Ciência e Tecnologia do Sudeste MG - Campus Barbacena \\ *Autor para correspondência, E-mail: wellyngton.vilela@ifsudestemg.edu.br
}

Resumo. Este trabalho busca avaliar o desempenho agronômico, bromatológico e econômico de um híbrido de milho para produção de silagem, considerando diferentes alturas de corte. O objetivo foi avaliar formas de obtenção de uma silagem com melhor valor nutritivo e produtividade de MS, procurando estudar os efeitos da elevação da altura de corte da silagem de milho de $0,15,30$ e $45 \mathrm{~cm}$ e também avaliar a quantidade composição mineral e valor econômico do material remanescente no solo após o corte para ensilagem. $\mathrm{O}$ experimento foi realizado no Núcleo de Agricultura do Instituto Federal do Sudeste de Minas Gerais - Campus Barbacena. O plantio do milho ocorreu no mês de novembro safra 2017/2018. A espécie utilizada foi um híbrido de ciclo precoce, semidentado, com duas proteínas inseticidas de Bt que propiciam controle da lagarta-docartucho, da lagarta-da-espiga e broca-do-colmo, além da tolerância ao glifosato. A colheita foi feita aos 109 dias, com $29 \%$ de MS com ponto de colheita determinado como base na linha do leite de 2/3 leitoso. Após a colheita, o material triturado foi ensilado em mini-silos experimentais, constituídos por cano de PVC, onde permaneceu por 60 dias. Abertos os silos as amostras coletadas foram encaminhadas para análises laboratoriais. $\mathrm{O}$ delineamento utilizado foi inteiramente casualizado contendo 07 parcelas experimentais igualmente divididas em 4 tratamentos. Os dados foram submetidos à análise pelo programa Sisvar 5.6, realizando-se uma análise de variância, em que as médias foram comparadas e testadas pelo método de Tukey, ao nível de 5\% de probabilidade. O material remanescente foi coletado, picado e moído sendo também posteriormente encaminhadas amostras para análises laboratoriais. A variação na altura de corte não afetou a composição bromatológica da silagem. As alturas de corte não influenciaram sobre a produção de MS da silagem. Ficou comprovado que, na produção da silagem, a altura de corte $30 / 45 \mathrm{~cm}$ retornou ao solo nutrientes que geram um valor financeiro considerável reduzindo assim os custos de produção e propiciou retorno de nutrientes como fósforo e potássio para o solo, com retorno financeiro estimado e possibilidade de favorecimento de um melhor manejo do solo em plantio de uma nova safra de milho ou outra cultura posterior.

Palavras chave: colheita, proteína bruta, silagem

\section{Evaluation of different cutting heights in corn silage}

Abstract. This work aims to evaluate the agronomic, bromatological and economic performance of a corn hybrid for silage production, considering different cutting heights. The objective was to evaluate ways of obtaining a silage with better nutritive value and 
productivity of DM, trying to study the effects of raising the cutting height of corn silage of $0,15,30$ and $45 \mathrm{~cm}$ and also to evaluate the amount of mineral composition and economic value of the material remaining in the soil after cutting to silage. The experiment was carried out at the Agricultural Center of the Federal Institute of the Southeast of Minas Gerais - Campus Barbacena. The corn planting took place in November 2017/2018 harvest. The species used was a precocious, early-cycle hybrid with two $\mathrm{Bt}$ insecticidal proteins that provide control of the carcass caterpillar, spider caterpillar and berry borer, as well as tolerance to glyphosate. The harvest was made at 109 days, with $29 \%$ DM with harvest point determined as base in the milky 2/3 milk line. After harvest, the crushed material was ensiled in experimental small silos, made of PVC pipe, where it remained for 60 days. Once the silos were opened the collected samples were sent for laboratory analysis. The experimental design was completely randomized, containing 7 experimental plots equally divided into 4 treatments. The data were submitted to analysis through the Sisvar 5.6 program. A variance analysis was performed, where the means were compared and tested by the Tukey method, at a 5\% probability level. The remaining material was collected, chopped and ground, and samples were also sent for laboratory analysis. The variation in cutting height did not affect the bromatological composition of the silage. The cut cutting heights did not influence on the silage DM production. It was verified that, in the silage production, the cutting height $30 / 45 \mathrm{~cm}$ returned to the soil nutrients that generate a considerable financial value thus reducing production costs and provided a return of nutrients such as phosphorus and potassium to the soil, with an estimated financial return and the possibility of favoring a better management of the soil in planting a new corn crop or another successor crop.

Keywords: Harvest, crude protein, silage

\section{Evaluación de diferentes alturas de corte en ensilado de maíz}

Resumen. Este trabajo tiene como objetivo evaluar el desempeño agronómico, bromatológico y económico de um híbrido de maíz para la producción de ensilaje, considerando diferentes alturas de corte. El objetivo de este estudio fue evaluar las formas de obtener um ensilaje com mejor valor nutritivo y productividad de MS, con el objetivo de estudiar los efectos de elevar la altura de corte del ensilado de maíz de $0,15,30$ y $45 \mathrm{~cm}$ y también evaluar la cantidad de composición mineral y valor económico del material restante del suelo después del corte del ensilaje. El experimento se llevó a cabo en el Centro Agrícola del Instituto Federal del Sureste de Minas Gerais - Campus Barbacena. La siembra de maíz tuvo lugar em la cosecha de noviembre de 2017/2018. La especie utilizada fue un híbrido precoz de ciclo temprano con dos proteínas insecticidas Bt que proporcionan control de la oruga de la carcasa, la oruga de la espiga y Diatraea saccharalis, así como la tolerancia al glifosato. La cosecha se realizó a los 109 días, con un 29\% de MS con un punto de cosecha determinado como base en la línea de leche 2/3 lechosa. Después de la cosecha, el material triturado se ensiló en mini-silos experimentales, hechos de tubería de PVC, donde permaneció durante 60 días. Una vez que se abrieron los silos, las muestras recolectadas se enviaron para análisis de laboratorio. El diseño experimental fue completamente al azar, conteniendo siete parcelas experimentales divididas en 4 tratamientos. Los datos se sometieron a análisis a través del programa Sisvar 5.6. Se realizó un análisis de varianza en el que las medias se compararon y probaron mediante el método de Tukey, con un nivel de probabilidad del 5\%. el restante del material se recolectó, se cortó y se trituró, y también se enviaron muestras para su análisis de laboratorio. La variación en la altura de corte no afectó la composición bromatológica del ensilaje. Las alturas de corte no influyeron en la producción de MS de ensilaje. Se verifico que, en la producción de ensilaje, la altura de corte de 30/45 cm incorporó nutrientes al suelo que generan un valor financiero considerable, lo que redujo los costos de producción y financiero estimado. Y la posibilidad de favorecer un mejor manejo del suelo al plantar u un nuevo cultivo de maíz u otro cultivo sucesor.

Palabras clave: Cosecha, proteína cruda, ensilaje 


\section{Introdução}

O milho e o sorgo são plantas forrageiras muito utilizadas na ensilagem, tendo em vista a alta capacidade produtiva dessas espécies e o valor nutritivo de suas silagens. A melhoria dessas características tem sido objetivo de muitos trabalhos de pesquisa (Avelino et al., 2011b; Brondani et al., 2006; Evangelista et al., 2005; Menezes et al., 2009).

Vários autores (Beleze et al., 2003; Jobim et al., 2010; Neumann et al., 2007) afirmam que a silagem de milho é tida como padrão e, geralmente, é tomada como referência para estimar o valor de outras silagens. No entanto, Johnson et al. (2002) afirmam que a produção e a qualidade do milho são variáveis de ano para ano, por serem influenciadas pela disponibilidade de água no solo.

De acordo com Evangelista \& Lima (2000) a cultura do milho, no Brasil, produz em média 35 t/ha de forragem verde, produção considerada baixa, sendo que o ideal para se obter menor custo é alcançar rendimentos acima de 40 t/ha.

Na região Sul do Estado de Minas Gerais, o milho é muito utilizado na alimentação de bovinos leiteiros, na forma de silagem. Avelino et al. (2011a) afirmam que, geralmente, as cultivares que produzem mais grãos são as recomendadas para a produção de silagem. A utilização da silagem de sorgo, nessa região, vem ganhando destaque nos últimos anos, devido a características como alta produtividade, alto valor nutritivo da forragem e custos competitivos, principalmente, quando a semeadura é feita na safrinha, época limitante à produção de milho, no Brasil.

O milho pode ser ensilado de várias maneiras diferentes, dentre elas: silagem da planta inteira e a silagem da parte superior, como alimentos volumosos e a silagem de espigas e de grãos úmidos, como alimentos energéticos (Jobim et al., 2010). A silagem da parte superior das plantas de milho pode ser uma opção, sendo obtida mantendo-se o corte mais próximo da espiga, recolhendo-se a parte superior da planta, garantindo uma silagem com alta participação de grãos na matéria seca (MS), com fibra mais digestível e maior conteúdo energético (Fugita et al., 2012; Neumann et al., 2007).

Este trabalho teve por objetivo avaliar o efeito da altura de corte do milho para ensilagem sobre o desempenho agronômico e bromatológico e econômico de um híbrido de milho para produção de silagem.

\section{Material e métodos}

O estudo foi realizado no Instituto Federal do Sudeste de Minas - Campus Barbacena, no Núcleo de Agricultura. A cidade de Barbacena, Minas Gerais, localiza-se a uma latitude 21 $1^{\circ} 133^{\prime \prime}$ " sul e a uma longitude $43^{\circ} 46^{\prime} 25^{\prime \prime}$ oeste e tem altitude de $1.164 \mathrm{~m}$ (Köppen \& Geiger, 1928). O relevo é plano com algumas montanhas, clima tropical de altitude. A temperatura média anual é de $18^{\circ} \mathrm{C}$, com índice pluviométrico anual é superior aos 1400 milímetros $(\mathrm{mm})$. A área experimental possui histórico de rotação lavoura-pecuária e a cultura antecessora ao milho foi brachiaria spp. em cobertura.

O solo utilizado para o plantio foi analisado no laboratório do Instituto Federal do Sudeste de Minas Gerais - Campus Barbacena. O preparo inicial do solo foi feito somente com o controle de plantas invasoras, vinte dias antes do plantio, com herbicida glifosato e não ocorreu a calagem da área (uso de calcário para correção do $\mathrm{pH}$ e como fonte de $\mathrm{Ca}$ e $\mathrm{Mg}$ ). O plantio do milho ocorreu em 27 de novembro de 2017. A espécie utilizada foi um híbrido de ciclo precoce, semi-dentado. Altura da planta varia de 230 a $250 \mathrm{~cm}$. Possui duas proteínas inseticidas de Bt que propiciam controle da lagarta-docartucho, da lagarta-da-espiga e broca-do-colmo, além da tolerância ao glifosato, permitindo o controle mais eficaz das plantas daninhas. Para o plantio foi utilizada uma plantadora, da própria instituição, de sistema de plantio direto a vácuo, de quatro linhas. O espaçamento usado foi de 0,8 metros entre plantas, aproximadamente, 4,9 sementes por metro onde gerou um estande inicial de 61.250 plantas por hectare.

Para a adubação de plantio, o cálculo foi feito de acordo como a recomendação do Manual de adubação de Minas Gerais ( $5^{\text {a }}$ aproximação). Foram utilizados adubos formulados de NPK. Foram utilizados 31,2 kg de N; 109,2 de P2O5; 64,4 de K2O. A adubação de cobertura foi dividida em 2 
etapas: $60 \mathrm{~kg}$ de $\mathrm{N}$ e $40 \mathrm{~kg}$ de $\mathrm{K}_{2} \mathrm{O}$, aos 21 dias após plantio (18/12/2017), fazendo a repetição com a mesma quantidade aos 32 dias de plantio, ou seja, em 29/12/17.

O controle de plantas invasoras foi realizado no dia 11/12/2017 com glifosato, aos 14 dias de plantio. A colheita foi feita aos 109 dias, no dia 16/03/2018 com 29\% de MS. O ponto de colheita foi determinado como base na linha do leite de $2 / 3$ leitoso, conforme pode ser visto na figura 1.

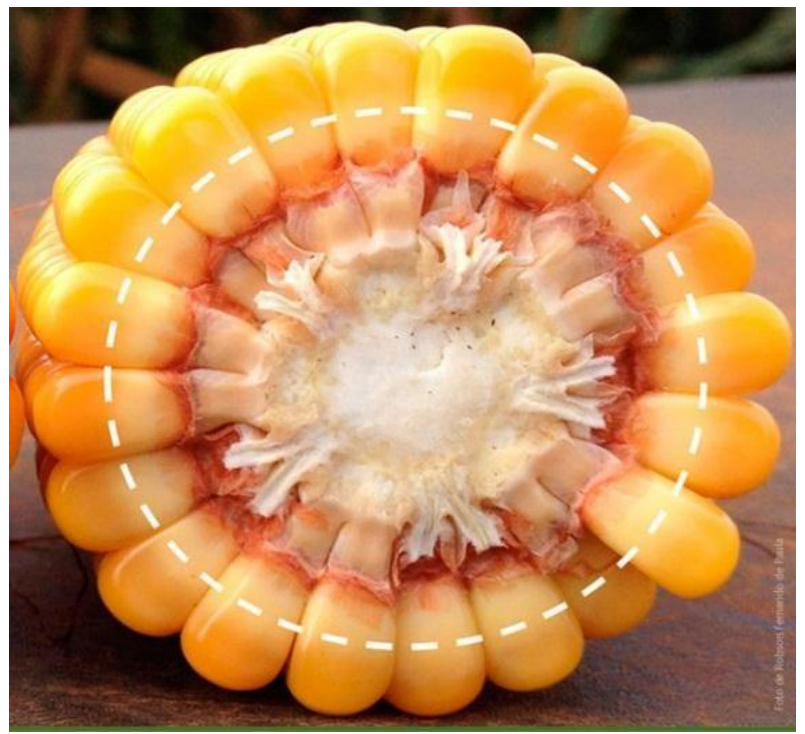

Figura 1. 2/3 da linha do leite.

Fonte: DuPont Pioneer Milho Crescimento e Desenvolvimento

As alturas de corte não influenciaram $(\mathrm{P}>0,05)$ na produção de MS da silagem (Tabela 1). A produção variou entre 22,21 toneladas de MS/ha para o corte de $0 \mathrm{~cm}$ e 24,75 toneladas de MS/ha para o corte a $45 \mathrm{~cm}$ de altura. Sendo observado uma redução de 10,3\% na produção neste presente estudo com a elevação da altura de corte de $0 \mathrm{~cm}$ para $45 \mathrm{~cm}$. Esta redução da produção também foi observada por Caetano et al. (2011) que observaram redução na produção de $13 \%$ com elevação da altura de colheita de 15 para $45 \mathrm{~cm}$. Este fato está relacionado com o material remanescente no solo (Tabela 2) que aumenta de acordo com o aumento da altura de corte.

Tabela1. Produção e composição bromatológica da silagem produzidas nas diferentes alturas de corte da planta de milho.

\begin{tabular}{lccccc}
\hline Altura de Corte & Produção (ton/MS/ha) & PB (\%) & FDN (\%) & FDA (\%) & MM (\%) \\
\hline 0 & 24,75 & 13,93 & 54,08 & 28,42 & 3,81 \\
15 & 21,83 & 13,93 & 55,62 & 29,21 & 4,91 \\
30 & 21,45 & 14,71 & 51,30 & 25,86 & 4,00 \\
45 & 22,21 & 14,67 & 52,12 & 26,19 & 3,49 \\
\hline$P$-valor & 0,6257 & 0,2942 & 0,3174 & 0,1315 & 0,1775
\end{tabular}

PB, proteína bruta; FDN, fibra em detergente neutro; FDA, fibra em detergente neutro; MM, matéria mineral.

Os teores de proteína bruta (Tabela 1) não foram influenciados também pela variação na altura de corte (P > 0,05), variando entre 13,9\% e 14,7\%. Oliveira et al. (2011) avaliando a composição nutricional da silagem de milho colhida em três alturas diferentes $(15,35$ e $55 \mathrm{~cm})$ não observaram também variação no teor de proteína bruta da silagem $(\mathrm{P}<0,05)$.

Os teores de matéria mineral, FDN e FDA também não sofreram efeitos das alturas de corte $(\mathrm{P}>$ $0,05)$. No entanto, foi observada uma redução de 3,6\% e 7,8\% do FDN e FDA, respectivamente com o aumento da altura de corte de $0 \mathrm{~cm}$ para $45 \mathrm{~cm}$. Este padrão também foi observado por Oliveira et al. (2011), onde os teores de FDN e FDA reduziram com o aumento da altura de corte. Esta redução pode ter ocorrido devido a maior proporção de grãos na massa ensilada. Sendo essa redução de fibras um fator importante, uma vez que o teor de fibras nos alimentos é um fator limitante para o consumo, devido ao maior tempo de esvaziamento do rúmen (Azevêdo et al., 2003; Freitas et al., 2006). Uma 
vez que a redução nos teores de fibras, principalmente a lignina, favorece a passagem do alimento pelo rúmen, uma vez que ela é um dos fatores limitantes na degradação da fibra (Van Soest, 1994).

Quanto a composição mineral do material remanescente no solo (Tabela 2) todos os minerais diferiram $(\mathrm{P}<0,0001)$ entre altura $0 \mathrm{~cm}$ e as demais alturas. $\mathrm{O}$ aumento da retenção de minerais com $\mathrm{o}$ aumento da altura de corte deve ao aumento do material remanescente no solo, o aumento da retenção de minerais também foi observado por Wietholter et al. (1994) que observaram uma tendência linear nos teores de minerais que permaneciam no solo com o aumento da altura de corte.

Tabela 2. Composição mineral do material remanescente no solo após a colheita para ensilagem, nas diferentes alturas de corte

\begin{tabular}{lccccccc}
\hline & Material remanescente (ton MS/ha) & $\mathrm{N} \mathrm{kg} / \mathrm{ha})$ & $\mathrm{P}(\mathrm{kg} / \mathrm{ha})$ & $\mathrm{K}(\mathrm{kg} / \mathrm{ha})$ & $\mathrm{Ca}(\mathrm{Kg} / \mathrm{ha})$ & $\mathrm{Mg}(\mathrm{kg} / \mathrm{ha})$ & $\mathrm{S}(\mathrm{kg} / \mathrm{ha})$ \\
\hline 0 & $0 \mathrm{C}$ & $0 \mathrm{C}$ & $0 \mathrm{~B}$ & $0 \mathrm{~B}$ & $0 \mathrm{~B}$ & $0 \mathrm{~B}$ & $0 \mathrm{~B}$ \\
15 & $1,88 \mathrm{~B}$ & $10,05 \mathrm{~B}$ & $0,71 \mathrm{~A}$ & $52,57 \mathrm{~A}$ & $3,86 \mathrm{~A}$ & $1,27 \mathrm{~A}$ & $0,83 \mathrm{~A}$ \\
30 & $2,41 \mathrm{AB}$ & $13,15 \mathrm{AB}$ & $0,72 \mathrm{~A}$ & $54,28 \mathrm{~A}$ & $4,55 \mathrm{~A}$ & $1,84 \mathrm{~A}$ & $1,02 \mathrm{~A}$ \\
45 & $3,50 \mathrm{~A}$ & $20,16 \mathrm{~A}$ & $1,04 \mathrm{~A}$ & $69,81 \mathrm{~A}$ & $6,51 \mathrm{~A}$ & $2,52 \mathrm{~A}$ & $1,18 \mathrm{~A}$ \\
\hline$P$-valor & $<0,0001$ & $<0,0001$ & $<0,0001$ & $<0,0001$ & $<0,0001$ & $<0,0001$ & $<0,0001$ \\
\hline
\end{tabular}

$\mathrm{N}$, nitrogênio; $\mathrm{P}$, fósforo; $\mathrm{K}$, potássio; $\mathrm{Ca}$, cálcio; $\mathrm{Mg}$, magnésio; $\mathrm{S}$, enxofre.

De acordo com a tabela 2 verifica-se que não houve diferenças nas quantidades de MS, fósforo, potássio de 0 a 15 e 15 a 30 (P > 0,05). Em questão ao custo da silagem por ha também não houve diferença maior. Quando comparamos as alturas de 0 e $15 \mathrm{com} 30$ a 45 podemos afirmar que houve um aumento no custo da produção de silagem, mas houve uma economia maior na ciclagem de nutrientes (Tabela 3).

Tabela 3. Custo de produção de silagem e ciclagem de nutrientes

\begin{tabular}{llcccccccc}
\hline $\begin{array}{l}\text { Material remanescente } \\
\text { (ton/MS/ha) }\end{array}$ & $\begin{array}{c}\text { Produção de CiclagemCiclagem } \\
\text { silagem (ton } \\
\text { MS/ha) }\end{array}$ & $\begin{array}{c}\text { de P } \\
(\mathrm{kg} / \mathrm{ha})\end{array}$ & $\begin{array}{c}\text { de K } \\
(\mathrm{kg} / \mathrm{ha})\end{array}$ & $\begin{array}{c}\text { Custo da Ton Custo da Ton } \\
\text { de P2O5 }\end{array}$ & de K2O & $\begin{array}{c}\text { Custo de } \\
\text { produção da } \\
\text { Silagem de } \\
\text { milho/ha }\end{array}$ & $\begin{array}{c}\text { Custo por Economia com } \\
\text { tonelada } \\
\text { de MS }\end{array}$ & $\begin{array}{c}\text { ciclagem de } \\
\text { nutrientes (ha) }\end{array}$ \\
\hline 0 & 0 & 24,75 & 0 & 0 & $\mathrm{R} \$$ & $\mathrm{R} \$$ & $4.550,00$ & 183,84 & 0 \\
$0-15$ & 1,88 & 21,83 & 0,71 & 52,57 & $1.400,00$ & $1.600,00$ & $4.550,00$ & 208,43 & 85,106 \\
$15-30$ & 2,41 & 21,45 & 0,72 & 54,28 & $1.400,00$ & $1.600,00$ & $4.550,00$ & 212,12 & 87,856 \\
$30-45$ & 3,5 & 22,21 & 1,04 & 69,81 & $1.400,00$ & $1.600,00$ & $4.550,00$ & 204,86 & 113,152 \\
\hline
\end{tabular}

Oliveira et al. (2011) afirmam que o corte mais elevado das plantas de milho quando comparado com o corte $0 \mathrm{~cm}$, como foi feito neste experimento, diminui o retorno econômico por tonelada de massa seca por hectare, o que precisa ser considerado na produção da silagem, pois os gastos com a recuperação do solo também precisam ser contabilizados. Seguindo assim, essa linha de raciocínio dos mesmos autores, podemos observar (Tabela 3) que a elevação da altura de corte contribuiu para aumentar a ciclagem de matéria orgânica no solo, o que resulta em melhora dos atributos físicos do mesmo, possibilitando ainda o retorno de grandes quantidades de potássio advindas dos internódios inferiores da planta.

Com a adoção do sistema de plantio direto e o ajuste da altura de corte no milho para ensilagem, é possível manejar melhor o solo, possibilitando assim sua conservação devido à manutenção e melhora das características físicas, químicas e biológicas do solo (Cabezas et al., 2000; Menezes et al., 2003). A manutenção de tais características vai exercer papel essencial na otimização das condições de germinação, emergência e a implantação da plântula, das culturas instaladas neste solo. Visto que o sistema conservará a estrutura do solo com baixa possibilidade de degradação e carregamento por água e vento. Com a estrutura preservada, conserva-se a porosidade do solo, proporção de infiltração de água e a fluidez do oxigênio para o interior do solo. Sabe-se se que quanto maior infiltração de água, menor será o risco de perdas por enxurrada e por erosão.

É importante destacar ainda que a presença de matéria orgânica é vital para a renovação do solo, pois a ação dos decompositores sobre essa matéria vai devolver ao solo os nutrientes necessários para que os seres vivos que o habitam possam adquirir energia para sobreviver e também para manter o equilíbrio e a conservação do mesmo. Todavia, na maioria das vezes, no cálculo dos custos da 
produção de silagem não é levado em consideração o valor econômico do material remanescente que, além de proteger o solo, o que por si só já é de grande importância porque irá proteger o solo de uma possível degradação, inviabilizando outro cultivo. Este fator pode ser comprovado com o experimento analisado, neste trabalho, conforme mostra a tabela 1, que a economia com os custos de produção da próxima safra de plantio de milho é significativa do ponto de vista financeiro. Ficou comprovado que, na produção da silagem, a altura de corte $30 / 45 \mathrm{~cm}$ retornou ao solo nutrientes que geram um valor financeiro considerável reduzindo assim os custos de produção e melhorando a vida útil do solo. Segundo Lepsch (2016), um solo, para ser considerado perfeito, precisa ter em sua constituição: 45\% de minerais, $25 \%$ de ar ocupando seus poros, $26 \%$ de água e 5\% de matéria orgânica e microrganismos, corroborando com a tese desse estudo.

\section{Conclusão}

As análises feitas neste estudo mostram que as características bromatológicas da silagem de milho melhoraram com elevação da altura de corte; contudo, aumentou o custo da tonelada de MS, inviabilizando o corte de 30 a $45 \mathrm{~cm}$.

A elevação da altura de corte propiciou retorno de nutrientes como fósforo e potássio para o solo, com retorno financeiro estimado e possibilidade de favorecimento de um melhor manejo do solo em plantio de uma nova safra de milho ou outra cultura sucessora. É necessário fazer mais pesquisas voltadas para avaliação de produção de matéria seca digestível por hectare.

\section{Referências bibliográficas}

Avelino, P. M., Neiva, J. N. M., Araujo, V. L., Alexandrino, E., Santos, A. C. \& Restle, J. (2011a). Características agronômicas e estruturais de híbridos de sorgo em função de diferentes densidades de plantio. Revista Ciência Agronômica, 42(2):534-541.

Avelino, P. M., Neiva, J. N. M., de Araujo, V. L., Alexandrino, E., Bomfim, M. A. D. \& Restle, J. (2011b). Composição bromatológica de silagens de híbridos de sorgo cultivados em diferentes densidades de plantas. Revista Ciência Agronômica, 42(1):208-215.

Azevêdo, J. A. G., Pereira, J. C., Carneiro, P. C. S., Queiroz, A., Barbosa, M. H. P., Fernandes, A. M. \& Rennó, F. P. (2003). Avaliação da divergência nutricional de variedades de cana-de-açúcar (Saccharum spp.). Revista Brasileira de Zootecnia, 32(6):1431-1442.

Beleze, J. R. F., Zeoula, L. M., Cecato, U., Dian, P. H. M., Martins, E. N. \& Falcão, A. J. D. S. (2003). Evaluation of five corn hybrids (Zea mays, L.) at different maturity stages. 2. Structural component concentrations and correlations. Revista Brasileira de Zootecnia, 32(3):538-545.

Brondani, I. L., Sampaio, A. A. M., Restle, J., Alves Filho, D. C., Freitas, L. D. S., Amaral, G. A., . . . Cezimbra, I. M. (2006). Composição física da carcaça e aspectos qualitativos da carne de bovinos de diferentes raças alimentados com diferentes níveis de energia. Revista Brasileira de Zootecnia, 35(5):2034-2042. doi: 10.1590/S1516-35982006000700022

Cabezas, W. A. R., Trivelin, P. C. O., Kondörfer, G. H. \& Pereira, S. (2000). Balanço da adubação nitrogenada sólida e fluida de cobertura na cultura de milho, em sistema plantio direto no Triângulo Mineiro (MG). Revista Brasileira de Ciência do Solo, 24(2):363-376.

Caetano, H., Oliveira, M. D. S., Freitas Júnior, J. E., Rêgo, A. C., Rennó, F. P. \& Carvalho, M. V. (2011). Evaluation of corn cultivars harvested at two cutting heights for ensilage. Revista Brasileira de Zootecnia, 40(1):12-19.

Evangelista, A. R., Abreu, J. G., Amaral, P. N. C., Pereira, R. C., Salvador, F. M., Lopes, J. \& Soares, L. Q. (2005). Composição bromatológica de silagem de sorgo (sorghum bicolor (L.) MOENCH) aditivadas com forragem de leucena (Leucaena leucocephala (LAM.) Dewit). Ciência $e$ Agrotecnologia, 29(2):429-435.

Evangelista, A. R. \& Lima, J. A. (2000). Silagens: do cultivo ao silo. Lavras, Minas Gerais, Brasil: Universidade Federaal de Lavras.

Freitas, A. W. P., Pereira, J. C., Rocha, F. C., Detmann, E., Barbosa, M. H. P., Ribeiro, M. D. \& Costa, M. G. (2006). Avaliação da divergência nutricional de genótipos de cana-de-açúcar 
(Saccharum spp.). Revista Brasileira de Zootecnia, 35(1):229-236.

Fugita, C. A., Prado, I. N., Jobim, C. C., Zawadzki, F., Valero, M. V., Pires, M. C. O. \& Françozo, M. C. (2012). Corn silage with and without enzyme-bacteria inoculants on performance, carcass characteristics and meat quality in feedlot finished crossbred bulls. Revista Brasileira de Zootecnia, 41(1):154-163.

Jobim, C. C., Branco, A. F., Gai, V. F., Calixto Junior, M. C. \& Santos, G. T. (2010). Quality of high moisture corn grain silage with addition of raw soybean grains and parameters of partial and total digestibility in cattle. Qualidade da silagem de grãos de milho com adição de soja crua e parâmetros de digestibilidade parcial e total em bovinos, 62(1):107-115.

Johnson, L. M., Harrison, J. H., Davidson, D., Mahanna, W. C., Shinners, K. \& Linder, D. (2002). Corn silage management: effects of maturity, inoculation, and mechanical processing on pack density and aerobic stability. Journal of Dairy Science, 85(2):434-444.

Köppen, W. \& Geiger, R. (1928). Klimate der Erde. Gotha: Verlag Justus Perthes. Wall-map $150 \mathrm{~cm} \times 200 \mathrm{~cm}$.

Lepsch, I. F. (2016). Formação e conservação dos solos. São Paulo, Brasil: Oficina de textos.

Menezes, J. F. S., Alvarenga, R. C., Andrade, C. L. T., Konzen, E. A. \& Pimenta, F. F. (2003). Aproveitamento de resíduos orgânicos para a produção de grãos em sistema de plantio direto e avaliação do impacto ambiental. Revista Plantio Direto, 9(1):30-35.

Menezes, L. F. G., Segabinazzi, L. R., Brondani, I. L., Restle, J., Arboitte, M. Z., Kuss, F. \& Rosa, J. R. P. (2009). Silagem de milho e grão de sorgo como suplementos para vacas de descarte terminadas em pastagem cultivada de estação fria. Arquivo Brasileiro de Medicina Veterinária e zootecnia, 61(1):182-189. doi: 10.1590/S0102-09352009000100026

Neumann, M., Mühlbach, P. R. F., Nörnberg, J. L., Restle, J. \& Ost, P. R. (2007). Efeito do tamanho de partícula e da altura de colheita das plantas de milho (Zea mays L.) sobre as perdas durante o processo fermentativo e o período de utilização das silagens. Revista Brasileira de Zootecnia, 36(5):1395-1405.

Oliveira, F. C. L., Jobim, C. C., Silva, M. S., Calixto Júnior, M., Bumbieris Júnior, V. H. \& Roman, J. (2011). Productivity and nutritional value of silage of corn hybrids with different heights of harvest. Revista Brasileira de Zootecnia, 40(4):720-727.

Van Soest, P. J. (1994). Nutritional ecology of the ruminant (Vol. 1). Ithaca, NY, USA: Cornell University Press.

Wietholter, S., Siqueira, O. J. F., Peruzzzo, G. \& Ben, J. R. (1994). Efeito de fertilizantes minerais e organominerais nos rendimentos de culturas e em fatores de fertilidade do solo. Pesquisa Agropecuária Brasileira, 29(5):713-724.

Recebido: 19 de setembro, 2019.

Aprovado: 11 de novembro, 2019.

Publicado: 29 de fevereiro, 2020.

Licenciamento: Este artigo é publicado na modalidade Acesso Aberto sob a licença Creative Commons Atribuição 4.0 (CC-BY 4.0), a qual permite uso irrestrito, distribuição, reprodução em qualquer meio, desde que o autor e a fonte sejam devidamente creditados. 